\title{
Lessening burden of rheumatic heart disease in Saint Vincent and the Grenadines
}

\begin{abstract}
Rheumatic heart disease is a disease of poverty and it disproportionately burdens developing countries like Saint Vincent and the Grenadines. The purpose of this paper is to assess the unique challenges facing the prevention of rheumatic heart disease in Saint Vincent and the Grenadines and provide recommendations based on evidence and best practices established by other similar countries experiencing the burden of this disease. A multifaceted approach to preventing rheumatic heart disease in Saint Vincent and the Grenadines appears to be the most efficacious. The implementation of school-based programs that focus on primary and secondary prevention will be advantageous in targeting children, some of the country's most vulnerable to rheumatic heart disease. The Ministry of Health in Saint Vincent and the Grenadines needs to continue to utilize partnerships with NGOs to ensure that knowledge, medical equipment, and skill transfers continue to take place so that the healthcare workforce and resources are strengthened. The utilization of task-shifting and standardization of screening and treatment will largely increase the ability for more isolated Grenadine Islands to be able to deliver the same care as healthcare works in the urban capital in Saint Vincent. In addition, a readily available supply of penicillin must be present on all inhabited islands. Lastly, the implementation of a country-wide registry system will allow the country to monitor and evaluate the individuals affected by rheumatic heart disease, in addition to the assessment of country-wide trends in incidence and prevalence of rheumatic heart disease.
\end{abstract}

Volume 7 Issue 4 - 2018

\author{
Lauren Turich \\ The George Washington University, USA
}

Correspondence: Lauren Turich, Milken Institute School of Public Health, The George Washington University, Villa, Saint Vincent and the Grenadines, USA, Email laurenturich@gwmail.gwu.edu

Received: July 06, 2018 | Published: August 09, 2018

\section{Background}

Despite the World Health Organization publishing guidelines for the prevention and treatment of rheumatic heart disease over the last 60 years, many middle and low-income countries, such as Saint Vincent and the Grenadines, continue to be disproportionately burdened by the disease. ${ }^{1}$ Perpetuating this burden is the social, political, and economic influences in Saint Vincent and the Grenadines. The specific challenges facing this island nation sets the stage for increased prevalence of rheumatic heart disease, thus making it a disease of poverty. Rheumatic heart disease proves to be a major public health concern as is inflicts disability and premature death upon those diagnosed with it. ${ }^{2}$ Social determinants of health largely influence whether a vulnerable population will be cured or left with a life-long burden of this disease. ${ }^{1}$ With access to proper health screening resources, healthcare systems of low and middle-income countries can properly screen for this disease and provide the simple and inexpensive treatment of Penicillin G. Saint Vincent and the Grenadines, a thirty-two-island nation in the West Indies, has incidence of rheumatic heart disease close to 200 times that of the United States. ${ }^{3}$ Understanding and analyzing the best practices of screenings techniques utilized by other countries, will allow Saint Vincent and the Grenadines to create effective screening programs for their vulnerable populations. For example, in New Zealand, school-based programs have shown to be efficacious in screening for acute rheumatic disease among their highrisk indigenous population. ${ }^{4}$ In addition to promoting familial acceptability of screening measures among school-aged children, the intervention reveled that echocardiographic screening proved to have high acceptability among families and with no negative psychological or physiological effects among those being screened. ${ }^{4}$ The purpose of this research is to review factors that make Saint Vincent and the Grenadines vulnerable to the disease, provide an overview of possible interventions that have been successful in similar populations and provide recommendations, such as evidence-based screening techniques to improve the preventative practices to decrease the incidence of this disease.

\section{Specific aims}

The specific aims of this critical analysis are as follows: (1) Assess what political, economic, and social factors make Saint Vincent and the Grenadines particularly vulnerable to rheumatic heart disease; (2) Identify the specific vulnerabilities of the high-risk populations of Saint Vincent and the Grenadines; (3) Assess the current preventative practices recommended by the World Health Organization and assessing what barriers has kept Saint Vincent and the Grenadines from implementing those recommendations; moreover, this research will assess the acceptability and negative effects of the preventative screening techniques utilized by other countries; (4) Provide recommendations about how the public health system of Saint Vincent and the Grenadines can address their risk factors for rheumatic heart disease through the utilization of best practices of other low and middle-income countries. This critical analysis is guided by the following research questions: (1) What social, economic, and environmental factors make the population of Saint Vincent and the Grenadines particularly vulnerable to rheumatic heart disease? (2) What are the current deficiencies that exist in the screening and preventing of rheumatic heart disease in Saint Vincent and the Grenadines? (3) What are primordial, primary, and secondary prevention techniques utilized by other middle and low-income counties that can be applied in Saint Vincent and the Grenadines? (4) Which best practices from other public health systems in other low and middle-income counties can be implemented in Saint Vincent and the Grenadines?

\section{Methods}

A narrative review of current research was conducted through various online databases including PubMed, Google Scholar, Center for Disease Control and Prevention, World Health Organization, and the George Washington University online library. I reviewed results from at least twenty peerreviewed resources. The phrases and keywords: "Acute rheumatic disease," "sequela of rheumatic heart disease," "Screening techniques of strep throat," "family acceptability," "screening for rheumatic heart disease," "screening techniques," "echocardiography," "high-risk populations," "best practices," "screening," "Saint Vincent and the Grenadines," "Strep throat," "treatment for strep throat," "long-term consequences of strep throat," "streptococcus pharyngitis," "chronic rheumatic heart disease," "primary prevention and 
programs or interventions," "primary prevention and successful programs," and "prevention and program or intervention and impact" will be used in association with Boolean operator "AND" in various combinations to find resources.

Inclusion criteria will include:

I. A relevant research published during or after 2012 .

II. Must be a scholarly peer-reviewed article.

III. Articles published in the English language only.

IV. National reports submitted by WHO, PAHO, the government of Saint Vincent and the Grenadines.

Exclusion Criteria will include:

a. Publications potentially used for marketing purposes.

b. Articles in foreign languages.

c. Articles dated prior to 2012 .

\section{Findings}

\section{Challenges specific to SaintVincent and the Grenadines}

Saint Vincent and the Grenadines is largely vulnerable to rheumatic heart disease because of its status as a lower-middle-income country and being classified as having an endemic pattern of rheumatic heart disease. ${ }^{1}$ Individua risk factors for Vincentians include their level of education, access to health services, overcrowding living conditions and income of the individual or their parents. ${ }^{5}$ Saint Vincent and the Grenadines as a country is particularly vulnerable to rheumatic heart disease as rheumatic heart disease is largely the result of overcrowding, poor sanitation, and other social determinants that directly and negatively affect health. ${ }^{1}$ Unfortunately, imported specialty services like pediatric cardiology are limited to once a year, depending on the availability of the United States' surgeons and physicians. The 2012 World Heart Federation recommends the use of echocardiograms, a sonogram of the heart, as a standardized approach to rheumatic heart disease screening. ${ }^{6}$ Because of limited resources and funding, screening of rheumatic heart disease with the aid of echocardiograms is limited to the largest island of Saint Vincent. As previously mentioned Milton Cato Memorial Hospital is the major medical center of the country and has the greatest access to funding and resources provided by international organizations. In order for Vincentians in the southern most Grenadines Islands, like Union Island, to receive the highest level of care in the country, they would have to fly or travel several hours by boat from their home island to Saint Vincent. Seeing as the combined poverty and vulnerable-to-poverty levels in Saint Vincent and the Grenadines is $48.2 \%$, it would be an overwhelming financial burden for Vincentians in the southernmost Grenadines Islands to have regular access to the medical services provided by Milton Cato Memorial Hospital (Third International Conference on Small Island Developing States-National Report, 2013).

The government of Saint Vincent and the Grenadines only provides healthcare benefits to "contributory," or tax-paying, Vincentians through the National Insurance Service. In addition, the National Insurance Service aids some noncontributory and elderly persons too bringing the total of healthinsured Vincentians to $36.5 \%$ in $2010 .^{7}$ High poverty rates, low-insured rates, geographical isolation, overcrowding and poverty are some of the contributory social determinants of health for many Vincentians. Creating a multifaceted approach to address these barriers to preventative health screenings, surrounding rheumatic heart disease, will largely address barriers that leave many Vincentians at risk for rheumatic heart disease.

\section{Epidemiology and mechanism of transmission of rheumatic heart disease}

A survey conducted by the Department of Child and Adolescent Health a the University of the West Indies (2012) reported that $77 \%$ of patients surveyed with rheumatic heart disease experienced the initial attack between five years and fifteen years of age. ${ }^{8}$ Furthermore, nearly $70 \%$ of those patients reported a recent Group A Streptococcal infection, the causal agent of rheumatic heart disease. ${ }^{8}$ The prevention of the transmission of Group A Streptococcal bacteria is of upmost importance as the long-term sequela of Group A Streptococcal bacterial infection, or more commonly known as Strep throat, is rheumatic heart disease. ${ }^{2}$ Children appear to be especially vulnerable to Streptococcal infection because the Group A Streptococcal bacteria is highly contagious (Mayo Foundation for Medical Education and Research, 2018). This bacteria can spread through respiratory droplets when a child coughs or sneezes, as two examples. Furthermore, this bacteria can also be easily spread through food and drinks. Group A Streptococcal bacteria can live on and be transferred through fomites such as doorknobs (Mayo Foundation for Medical Education and Research, 2018). Children in close contact with sick children, for instance in a school or home environment, allow for efficient transmission of the bacteria among children.

\section{Pathophysiology of rheumatic heart disease}

A component of Group A Streptococcal bacteria is a protein called M protein. M protein has a very similar microscopic structure to the microscopic structures of heart values. Unfortunately, the body's immune system cannot differentiate the M protein of Group A Streptococcal bacteria and the microscopic structure of the heart valve. As a result, the body's immune system attacks them both. This complication of Group A Streptococcal bacterial infection is termed rheumatic heart fever. ${ }^{9}$ The repeated episodes of rheumatic heart fever will eventually cause long-term damage to heart valves, which results in rheumatic heart disease. Trained medical professionals can visualize the damage to the heart valves through echocardiograms, which is why the World Heart Federation recommends echocardiograms as a standardized approach to rheumatic heart disease screening. ${ }^{6}$ The long term negative effects of untreated rheumatic heart disease include heart failure, stroke, and inflammation of the heart. In developing countries like Ethiopia, it has been reported that $70 \%$ of patients with rheumatic heart disease have died before the age of $26 .{ }^{10}$ In addition to improving the length and quality of life among the most vulnerable populations, preventative screening and treatments significantly reduce healthcare costs. Manji \& others $2013^{10}$ reported over $\$ 51$ million a year was spent on one hundred low-income patients with diagnosed rheumatic heart disease treatment in Brazil.

\section{Prevention of rheumatic heart disease}

Primary prevention techniques require proper hygiene practices among individuals with the infection. Washing hands, hygienic sneezing techniques, and not sharing cups and cutlery with a sick person are all important and effective forms of primary prevention (Mayo Foundation for Medical Education and Research, 2018). Unfortunately, these behaviors are not regularly practiced by school-aged children, which makes this population especially vulnerable to the spread of Group A Streptococcal bacteria.

Currently, there is no vaccine for Group A Streptococcal bacteria. The lack of vaccine development and widespread availability is partially the result of little economic incentive from the vaccine development industry. The development of a Group A Streptococcus vaccine has been in development since 1960s, however, still no vaccine is available. High-income countries have decreased funding for vaccine development as rheumatic heart disease simply isn't prevalent in their population. ${ }^{11}$ The primary population utilizing the vaccine would be from middle and low-income countries, like Saint Vincent and the Grenadines, which has little financial benefit for the vaccine development industry. ${ }^{9}$ Pressure needs to be placed on those in power to continue to fund the development of vaccine development for Group A Streptococcus as vaccine development is the best chance for eradication of rheumatic heart disease. ${ }^{12}$ A form of secondary prevention manifests as echocardiograms assessing the presence of a diseased heart valve. An echocardiogram allows medical workers to look at the patient's heart to see whether there is any evidence of damaged heart valves. A common sequela of Group A Streptococcal bacterial infection is for antibodies, created by the immune system of the infection person, to unintentionally attack the infected person's own heart valves as previously mentioned.

\section{Resources currently available in Saint Vincent and the Grenadines}

Milton Cato Memorial Hospital of Saint Vincent and the Grenadines was 
donated one echocardiogram in $2017 .{ }^{13}$ There is no evidence to suggest other echocardiograms exists in the more isolated health posts in the Grenadine Islands. In the absence of an echocardiogram, medical professionals can assess the patient's physical presentation for either Strep throat or rheumatic heart fever using basic physical examination techniques. Unfortunately, the ability to perform the basic screening exam is dependent on whether the patient and their parent(s) seek medical assistance. Furthermore, treatment of Strep throat and/or rheumatic fever requires penicillin. The initial screening and subsequent treatment for Strep throat and/or rheumatic fever require financial resources, medical infrastructure, medical professional training, and geographical proximity. These factors and others are specifically challenging for those living in a developing country like Saint Vincent and the Grenadines, which boasts a poverty rate of $48.2 \%{ }^{8}$ and a health insurance coverage rate of only $36.5 \%{ }^{7}$

\section{Recommended screening and treatment practices for rheumatic heart disease as per evidence}

The World Health Organization firmly recommends the utilization of echocardiography as it can be performed remotely and at a low cost. ${ }^{14}$ The 2012 World Heart Foundation criteria for the echocardiographic diagnosis of rheumatic heart disease can be found on Table 1 below. The 2012 World Heart Foundation criteria is an internationally developed, evidence-based approach to the echocardiographic diagnostic guideline for rheumatic heart disease. With the objective and prompt recognition of rheumatic heart disease via echocardiography, patients can immediately begin their secondary prevention regimen, which includes recurrent penicillin injections. ${ }^{14}$ Manji \& others $2013^{10}$ suggest that primary prophylaxis may be less cost-effective than echocardiographic screening followed by secondary prevention. Specific barriers to the echocardiogram-centered approach to rheumatic heart disease prevention is the lack of diagnostic equipment. Focus from international organizations, international institutions and the federal government to generate the funding needed to ensure inhabited islands in Saint Vincent and the Grenadines have access to echocardiograms.

Table I: Summary of recent screening studies examining the sensitivity and specificity of simplified diagnostic criteria when compared to the reference approach (images obtained using standard portable echocardiography and interpreted by experienced cardiologists with expertise in rheumatic heart disease using the full 2012 World Heart Federation criteria)

Source: Dougherty, S., Khorsandi, M., \& Herbst, P (2017). Rheumatic heart disease screening: Current concepts and challenges.Annals of Pediatric Cardiology, I0(I), 39-49.1:Ni:10.4103/0974-2069.19705I.

Two studies used different diagnostic criteria given that they predated the WHF criteria. 'All disease: Borderline RHD + definite RHD. Owing to nonstandard criteria, this does not apply to the studies by Mirabel et at.," \& Colquhoun et al. 20I3, 'Both studies compared the performance of two nurses using HAND on the same population, therefore there are two separate values for sensitivity and specificity (the study by Ploutz et al. 2016 compared the performance of two nurses using HAND on two different populations), -Diagnostic criteria: 200 I WHO Doppler criteria plus morphological criteria ( of leaflet thickening, restricted leaflet mobility, and thickened, shortened chordae) ${ }^{(8115}$ Diagnostic criteria:WHO and NIH RHD working party diagnostic guidelines.m SD: Standard deviation, RHD: Rheumatic heart disease, STAND: Standard portable echocardiography, HAND: Handheld echocardiography, MR: Mitral regurgitation, AR: Aortic regurgitation, PPV: Positive predictive value, CW: Continuous wave Doppler,WHF:World Heart Federation, WHO:World Health Organization, NIH: National Institutes of Health.

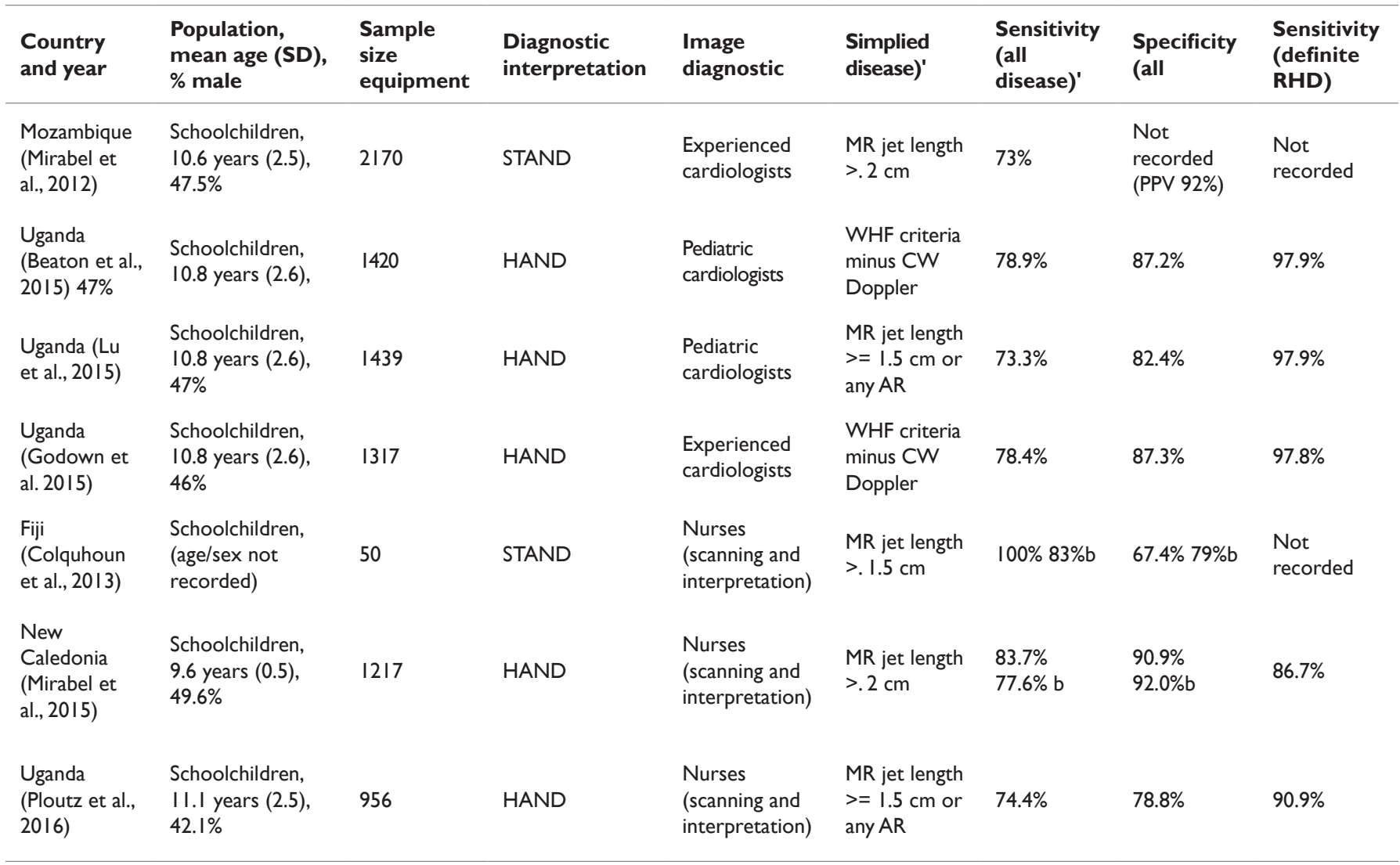




\section{Acceptability of utilization of echocardiograms in screening interventions}

Northern Uganda implemented a school-based echocardiogram screening approach to assess the acceptability of the experience the children and teachers had during the screening event. Of the 255 students (mean 10.7 years; $48 \%$ male) and 35 teachers screened in this study, $95 \%$ of the students and $100 \%$ of the teachers "were happy to have participated in the screening; however, students reported feeling scared (35\%) and nervous (48\%) during the screening process". Results from surveys obtained from the school-based screening for rheumatic heart disease in Northern Uganda is as follows (Table 2) (Table 3).

Table 2: Students' experience of school-based echocardiographic screening for rheumatic heart disease $(n=255)$

Source: Ploutz, M., Aliku,T., Bradley-Hewitt, T., Dantin, A., Lemley, B., Gillespie,

C.W., ... Beaton, A. (2017). Child and teacher acceptability of school-

based echocardiographic screening for rheumatic heart disease in uganda.

Cardiology in the Young, 27(I), 82. doi:10.1017/SI04795 I I 16000159

\begin{tabular}{llll} 
& Positive & Neutral & Negative \\
\hline $\begin{array}{l}\text { I am happy that my heart was } \\
\text { checked }\end{array}$ & $95 \%$ & $1 \%$ & $4 \%$ \\
$\begin{array}{l}\text { I wanted more privacy when they } \\
\text { were checking my heart }\end{array}$ & $40 \%$ & $8 \%$ & $52 \%$ \\
$\begin{array}{l}\text { I felt scared when they people } \\
\text { were checking my heart }\end{array}$ & $35 \%$ & $9 \%$ & $56 \%$ \\
$\begin{array}{l}\text { I would tell my friend that checking } \\
\text { my heart is easy }\end{array}$ & $80 \%$ & $4 \%$ & $17 \%$ \\
$\begin{array}{l}\text { I felt nervous when the people } \\
\text { were checking my heart }\end{array}$ & $48 \%$ & $6 \%$ & $46 \%$ \\
$\begin{array}{l}\text { The people told me what they } \\
\text { were doing to do before they did it }\end{array}$ & $75 \%$ & $7 \%$ & $18 \%$ \\
$\begin{array}{l}\text { I felt safe when the people were } \\
\text { checking my heart }\end{array}$ & $69 \%$ & $13 \%$ & $18 \%$ \\
$\begin{array}{l}\text { The people that checked my hearts } \\
\text { were nice to me }\end{array}$ & $82 \%$ & $3 \%$ & $15 \%$ \\
$\begin{array}{l}\text { The people who checked my heart } \\
\text { talked to me }\end{array}$ & $81 \%$ & $4 \%$ & $15 \%$ \\
$\begin{array}{l}\text { I understood what was going to } \\
\text { happen when they checked my } \\
\text { heart }\end{array}$ & $67 \%$ & $9 \%$ & $24 \%$ \\
\hline
\end{tabular}

Table 3:Teachers' experience of school-based echocardiographic screening for rheumatic heart disease $(n=255)$

Source: Ploutz, M., Aliku, T., Bradley-Hewitt, T., Dantin,A., Lemley, B., Gillespie, C.W., ... Beaton, A. (2017). Child and teacher acceptability of schoolbased echocardiographic screening for rheumatic heart disease in uganda. Cardiology in the Young, 27(I), 82. doi:10.1017/SI04795III6000I59

\begin{tabular}{llll} 
& Positive & Neutral & Negative \\
\hline $\begin{array}{l}\text { The children were scared on the day } \\
\text { of screening }\end{array}$ & $20 \%$ & $37 \%$ & $43 \%$ \\
$\begin{array}{l}\text { The screening was disruptive } \\
\text { I am pleased the children had their }\end{array}$ & $23 \%$ & $9 \%$ & $69 \%$ \\
$\begin{array}{l}\text { hearts checked } \\
\text { I would tell teachers at other schools } \\
\text { to allow this program }\end{array}$ & $100 \%$ & $0 \%$ & $0 \%$ \\
$\begin{array}{l}\text { I wish the screening had NOT taken } \\
\text { place }\end{array}$ & $9 \%$ & $0 \%$ & $91 \%$ \\
$\begin{array}{l}\text { This was a worthwhile activity } \\
\begin{array}{l}\text { Parents were pleased that the } \\
\text { screening took place }\end{array}\end{array}$ & $86 \%$ & $9 \%$ & $6 \%$ \\
\hline
\end{tabular}

\begin{tabular}{llll}
\hline & Positive & Neutral & Negative \\
\hline $\begin{array}{l}\text { The children were prepared well for } \\
\text { the screening activity }\end{array}$ & $86 \%$ & $6 \%$ & $9 \%$ \\
$\begin{array}{l}\text { There were too many people at the } \\
\text { school }\end{array}$ & $66 \%$ & $3 \%$ & $31 \%$ \\
$\begin{array}{l}\text { I understood what was going to } \\
\text { happen when the team... }\end{array}$ & $63 \%$ & $11 \%$ & $26 \%$ \\
\hline
\end{tabular}

\section{Best practices of other low-to-middle income} countries

In the setting of Saint Vincent and the Grenadines, it is important to assess the cost-effective prevention techniques utilized by other countries that would be equally beneficial to the specific challenges vulnerable populations in Saint Vincent and the Grenadines face. Assessing the best practices of countries that also have a few medical resources, inadequately trained medical personnel, geographic isolation of patients, and low-income among patients will ultimately benefit Saint Vincent and the Grenadines more. In a costeffectiveness acceptability report published by Irlam \& others $2012{ }^{15}$ regarding the high prevalence of rheumatic heart disease in South Africa, it was proposed to simply treat everyone within a high-risk population. Irlam \& others $2012^{15}$ argue that treating everyone with the inexpensive treatment of an intramuscular injection of penicillin is effective and cost-efficient as each injection costs only USD \$1; furthermore, this strategy has a sensitivity of $100 \%$. In largescale utilization of penicillin in Puerto Rico, Guadeloupe, Martinique, and Cuba for rheumatic heart disease, there were no reports of drug resistance to penicillin. ${ }^{15}$ A cost-effective analysis study, undertaken over ten years in Cuba, suggested the most efficacious and cost-effective approach to the management of rheumatic heart disease are as follows: (1) increase supply of penicillin to all district hospitals and health posts (2) improve medical worker education surrounding the recognition and treatment of Group A Streptococcal infections (3) integrate a registry system that is accessible to all healthcare facilities in the country. ${ }^{16}$ The Rwandan healthcare system utilizes volunteer expatriate teams that transfer knowledge and training to local healthcare providers in Rwanda. The premise of this program is to create a foundation in which Rwanda gradually transitions to a self-sustaining, comprehensive cardiac care program that focuses on recognition and treatment of all cardiac cases, in addition to rheumatic heart disease. ${ }^{17}$ Furthermore, this model allows for Rwandan healthcare providers, the Rwandan Ministry of Health and Ivy Leaguetrained medical volunteers exchange ideas to ultimately create a sophisticated approach to skill transfer, problem solving, and idea sharing. ${ }^{17}$

\section{Recommendations for the prevention of rheumatic heart disease in Saint Vincent and the Grenadines}

The most efficacious approach for screening for rheumatic heart disease is using the echocardiogram. Echocardiograms are preferred to other screening methods, like screening for heart murmurs, because echocardiograms can be sensitive to subclinical components of rheumatic heart disease. ${ }^{11}$ Previously, physicians and other trained health care workers would utilize a stethoscope to auscultate or listen for evidence of heart valve disease, related to rheumatic heart disease, in the form of a heart murmur. Echocardiography has demonstrated that evidence rheumatic heart disease can be present in the absence of an audible heart murmur. ${ }^{5}$ Therefore, many cases of rheumatic heart disease were missed, as a result of inadequate screening techniques. Echocardiography can decrease the amount of missed cases because echocardiograms are more sensitive to rheumatic heart disease presentation.

The prevention of rheumatic heart disease is the most appealing option of sustainable disease control in developing nations. The severe burden upon individuals and the development of low and middle-income countries needs to be realized by the governments and other stakeholders in endemic regions. Without the full and aggressive support by governments, NGOs, and other stakeholders, prevention of rheumatic heart disease in Saint Vincent and the Grenadines will continue to be weak. With proper access to primary 
prophylaxis, rheumatic heart disease would be avoided entirely as screening for strep throat would be able to take place. In the event a child reported a sore throat, microbiological studies could be conducted on a throat culture to confirm Group A Streptococcus as the etiological agent. Countries with plentiful resources can utilize a Rapid antigen test to detect in minutes the presence of Group A Streptococcus $;{ }^{18}$ conversely, resource poor healthcare systems may be forced to utilize a throat culture, which may take several days to gain a result. A gap in care leaves patients vulnerable to loss to follow-up. Secondary prophylaxis has demonstrated the most cost-effective approach to rheumatic heart disease prevention. ${ }^{11}$ Secondary prophylaxis is defined as an attempt to prevent asymptotic disease from progressing into systematic disease. Secondary prophylaxis is more advantageous than primary prophylaxis, in the context of rheumatic heart disease, as primary prophylaxis requires the microbiology lab services that are not reliably accessible in a decentralized, multi-island nation like Saint Vincent and the Grenadines. Secondary prophylaxis, in the form of penicillin prophylaxis, requires access to readily available penicillin, which is difficult to secure in resource-poor healthcare settings. ${ }^{5}$ Penicillin prophylaxis has been utilized by the Rheumatic Fever/Rheumatic Heart Disease Control Programme in Jamaica. Although there is always the risk of an allergic reaction, following penicillin administration, the Rheumatic Fever/Rheumatic Heart Disease Control Programme in Jamaica found that, "rheumatic fever recurred in $8(0.45 \%)$ of 1790 patients while on regular [penicillin] prophylaxis compared with $11(11.5 \%)$ of 96 who were not". ${ }^{8}$ As health care providers and public health advocates it is prudent to consistently weight the benefits and risks of interventions such as penicillin injections. RHDAustrailia $2018^{19}$ reports that potential risks of penicillin injections include pain at the injection site and hypersensitivity reactions to penicillin. Penicillin prophylaxis has been successfully utilized, in conjunction with register-based rheumatic heart disease control programs in Australia, Egypt, Taiwan, Brazil, Uganda, and South Africa. ${ }^{2}$ Penicillin prophylaxis has shown to be advantageous because it slows the progression of strep throat and acute rheumatic fever to rheumatic heart disease. Moreover, Group A Streptococcus has not demonstrated any antimicrobial resistance against penicillin. ${ }^{20}$ However, even with the implementation of register-based rheumatic heart disease control programs in Australia, Egypt, Taiwan, Brazil, Uganda, and South Africa, compliance with penicillin prophylaxis treatment only averaged at $30 \% .{ }^{21}$ Poor compliance with penicillin prophylaxis was a result of a lack of several factors including "lack of awareness or understanding of the disease and long distance to travel for receiving prophylaxis". ${ }^{22}$

Standardizing the criteria for rheumatic heart disease is another important component to rheumatic heart disease screening. Dr. T. D. Jones first standardized the screening approach to rheumatic heart disease when he established the Jones Criteria in 1944. ${ }^{5}$ The five components to the Jones Criteria include: migrating polyarthritis, pancarditis, subcutaneous nodules, erythema marginatum, and Sydenham chorea. Although this physical examination technique, in addition to the auscultation of heart murmurs, is utilized often for the primary screening of rheumatic heart disease, subclinical cases of wellestablished rheumatic heart disease remain undiagnosed. The implementation of the echocardiogram allowed for subclinical cases of rheumatic heart disease to be discovered by medical workers as it is a more sensitive screening tool. With advance technology available for rheumatic heart disease, upgrades the standardized approach to screening have taken place. Secondary screening has utilized the 2012 World Heart Federation criteria (Table 4) as a guide to a systematic and standardized approach to rheumatic heart disease screening, with the use of echocardiogram technology. The 2012 World Heart Federation criteria, alongside echocardiogram utilization, have been widely adopted in screening for rheumatic heart disease in school-going children in endemic countries in Africa. ${ }^{6}$ Northern Uganda proved that the acceptability of school-based screening for rheumatic heart disease with the utilization of the echocardiogram. In addition to high rates of acceptability among the students and teachers, well over two hundred children and adults were screened for rheumatic heart disease, as previously discussed. With implementation programs that allow increased access to especially vulnerable populations in endemic areas, more subclinical cases can be caught, and treatment can begin more expeditiously. Several advantages exist with echocardiogram technology. Echocardiograms have become rather compact and portable; moreover, probes can be attached to "smart devices" which will continue to increase portability and reduce initial costs for the product. ${ }^{2}$ In addition, there are larger, more cumbersome model that are available as well.

Table 4: The abridged World Heart Federation diagnostic screening criteria for rheumatic heart disease 38

RHO: Rheumatic heat disease, MR: Mitral regurgitation, AR:Aortic regurgitation, MV: Mitral valve, AV:Atrioventricular, AMVL:Anterior mitral valve leaflet, MS: Mitral stenosis

Echocardiographic criteria for RHD in individuals $\leq 20$ years For definite RHD (either A, B, C, or D)

A:A: Pathological MR and $\geq 2$ morphological features of $\mathrm{RHO}$ of the MV

B: MS (mean gradient $\geq 4 \mathrm{mmHg}$ )

C: C: Pathological AR and $\geq 2$ morphological features of RHD of the AV

$\mathrm{D}: \mathrm{D}:$ Borderline disease of both the $\mathrm{MV}$ and $\mathrm{AV}$

For borderline RHD (either A, B, or C)

$A: \geq 2$ morphological features of RHD of the MV without pathological MR or MS

B: Pathological MR

\section{C: Pathological AR}

Echocardiographic criteria for pathological regurgitation Doppler echocardiographic criteria for MR (all 4 must be met) Seen in 2 views

In at least I view, jet length $\geq 2 \mathrm{~cm}$

Velocity $\geq 3 \mathrm{~m} / \mathrm{s}$ for I complete envelope

Pan-systolic jet in at least I envelope

Doppler echocardiographic criteria for AR (all 4 must be met) Seen in 2 views

In at least I view, jet length $\geq I \mathrm{~cm}$

Velocity $\geq 3 \mathrm{~m} / \mathrm{s}$ in early diastole

Pan-diastolic jet in at least one envelope

Echocardiographic criteria for morphological features of RHD Features in the MV

AMVL thickening $\geq 3 \mathrm{~mm}$ ( $\geq 4 \mathrm{~mm}$ if aged $2 \mathrm{I}-40$ years, $\geq 5 \mathrm{~mm}$ if aged over 40 years)

Chordal thickening

Restricted leaflet motion

Excessive leaflet tip motion during systole Features in the AV

Irregular or focal thickening

Coaptation defect

Restricted leaflet motion

Prolapse

Disadvantages with echocardiographic screening for rheumatic heart disease do exist. In addition to the initial cost of the echocardiogram devices, it is necessary to ensure that local resources allow for continued maintenance for the echocardiogram machines. Furthermore, advances in technology, such as attaching an echocardiogram probe to a smart phone may not be appropriate and sustainable solution in geographically isolated endemic areas that may not have reliable access to technology. Furthermore, a focus on task-shifting will be of upmost importance to the implementation of this technology.

Task-shifting is the delegation of a clinical task from a specialized clinician, 
like a cardiologist, to a less-specialized clinical, like a health worker. Task shifting using nurses with echocardiographic training is an advantageous approach to ensuring the echocardiogram technology is available in geographically isolated and resource-limited settings. "Overall sensitivity for all disease ranged from $74.4 \%$ to $100 \%$ and specificity was $67.4 \%-92 \%$. Sensitivity for definite RHD was high at $86.7 \%-93.3 \% "{ }^{2}$. With proper training Saint Vincent and the Grenadines can have specialists train nurses and other health workers in the most remote islands to be able to utilize echocardiograms to properly screen for rheumatic heart disease. Engelman \& colleges $2016^{23}$ assessed seven nurses in eight different schools containing 2004 children in Fiji between September 2012 and September 2013. During this time, Engelman and colleges assessed the accuracy of non-expert operators, like nurses, and their ability to screen for RHD via echocardiography. Engelman \& colleges $2016^{23}$ reported sensitivity of individual nurses ranged from $66.7 \%$ to $100 \%$ and specificity of $74.0 \%$ to $93.7 \%{ }^{23}$ One particular approach to training non-expert operators and their ability to RHD screening via echocardiograms include the administration of a standardized, computerbased training course. ${ }^{24}$ Beaton \& colleagues $2016^{24}$ conducted a study in Brazil to assess the efficacy of implementing a standardized, computerbased training course to six non-experts, which included medical students, nurses, and bio-technicians. The three-week training course had a high rate of accessibility among those that attended; furthermore, the program reduced costs and time needed to train non-experts (Beaton et al., 2016). The results of the intervention revealed a combined sensitivity of $83 \%(95 \%$ CI $76 \%$ to $89 \%)$ and a specificity of $85 \%$ (95\% CI $82 \%$ or $87 \%$ ) for detecting any RHD ${ }^{24}$ Moving forward, leaders in vaccine development need to understand the importance of vaccine development. Monetary resources must continue to be directed towards the development of a Group A Streptococcus vaccine. Sharma \& Nitsche-Schmitz $2014{ }^{17}$ name one major challenges with Group A Streptococcus vaccine: there are so many different variations of the bacteria, that it would be difficult to ensure the vaccine protects against all varieties of the bacteria. One option is to take a similar approach to that of the influenza and HPV vaccine, which includes combining several different combinations of the bacteria in one vaccine, to anticipate which bacterial variation may be most dangerous. A second approach would be to make several different regionspecific vaccines that would provide better coverage in specific areas. In either scenario, resources will have to be dedicated for surveillance of the vaccines to ensure the proper vaccines are being administered; furthermore, constan redevelopment may be necessary too, in the event cross contamination between different regional variants manifest. ${ }^{25-33}$

\section{Conclusion}

There are efficacious programs in place in other low-income countries that are lessening the burden of rheumatic heart disease in their respective countries. Ultimately, the prevention of rheumatic heart disease must be given priority by the central and local governments and Ministry of Health of Saint Vincent and the Grenadines for any intervention to be implemented. Furthermore, high-income countries need to prioritize the need to continue to direct effort and funding into the prevention of rheumatic heart disease as they hold the monopoly of advancing healthcare in the world. Saint Vincent and the Grenadines needs to continue to work closely with already existing NGO alliances to locally develop the current prevention techniques being practiced within the country's healthcare infrastructure. Saint Vincent and the Grenadines poses many unique challenges to the prevention of rheumatic heart disease. In addition to geographic isolation, many health workers and other medical resources are largely limited to the largest island of Saint Vincent. This dense and limited distribution of medical resources and personnel to the largest island greatly and negatively effects the more geographically isolated islands of the Grenadines. For that reason, it is important to consider the unique circumstances this country faces, that other countries reviewed in this paper do not equally experience.

\section{Limitations}

Although this paper assesses the rheumatic heart disease prevention program in over ten other countries, none of the other countries assessed are composed of thirty-two islands. Therefore, a major limitation of this paper is the result of unique circumstances of the countries' geographical makeup that most other countries and their respective healthcare system simply do not encounter. Therefore, the intervention proposed may not be directly translatable to Saint Vincent and the Grenadines as the country's unique geographical composition may hinder some components of the recommendations.

Furthermore, a second limitation to this paper is that there is not a readily available amount of information regarding the progress of rheumatic heart disease prevention in Saint Vincent and the Grenadines as there is not a countrywide registry and monitoring system in place. Much of the data analyzed for this paper was extracted from Caribbean-region resources. Very little data of this topic in Saint Vincent and the Grenadines specially is available in research databases. Utilizing evidence assembled from the best practices of other lowincome countries is an advantageous first step in addressing rheumatic heart disease in Saint Vincent and the Grenadines. As previously mentioned, it may be a challenge to directly translate all the best practices from one country's prevention programs into Saint Vincent and the Grenadines, however, it is certainly a good first step.

\section{Future direction}

The Ministry of Health in Saint Vincent and the Grenadines needs to analyze what unique challenges that exist within its current healthcare infrastructure that prevents the aggressive attempts at rheumatic heart disease prevention. Unfortunately, the country has other major competing healthcare crisis, which include an HIV/AIDS epidemic that largely distracts time, resources, and energy from other health prevention programs, which include rheumatic heart disease. If the Ministry of Health can assess the challenges that exist within their healthcare infrastructure and create country-specific solutions based in the best practices and evidence established by other countries, Saint Vincent and the Grenadines stands a chance in improved prevention of rheumatic heart disease.

Rheumatic heart disease prevention needs to be a priority for both high and low-income countries because some of the most vulnerable to this disease are children. In addition to the moral and ethical need to protect any country's vulnerable children, all countries need to realize the long-term implications of early death and disability in vulnerable county's future workforce and leaders. Preventing rheumatic heart disease allows the most vulnerable populations to have a quality of life. Preventing rheumatic heart disease allows vulnerable populations to continue to go to school and remain in the workforce. Simple screening techniques, standardization of care, and treatment can save millions of dollars for those burden to pay for healthcare costs and ultimately save lives. Focusing on the prevention of rheumatic heart disease in low-income countries like Saint Vincent and the Grenadines is important and necessary for the future of vulnerable Vincentians and others in similar in other vulnerable countries across the world.

\section{Ethical considerations}

No ethical considerations.

\section{Acknowledgements}

The author would like to thank the Milken Institute School of Public Health at the George Washington University for posing the research opportunity and Dr. Nisha A. Sachdev, DrPh, PsyD for her proofreading and guidance throughout the research.

\section{Conflict of interest}

The author has no conflicts of interests in this work.

\section{References}

1. Watkins DA, Johnson CO, Colquhoun SM, et al. Global, Regional, and National Burden of Rheumatic Heart Disease, 1990-2015. N Engl J Med. 2017;377(8):713-722.

2. Dougherty S, Khorsandi M, Herbst P. Rheumatic heart disease screening: Current concepts and challenges. Annals of Pediatric Cardiology. 2017;10(1):39-49.

3. Saint Vincent \& the Grenadines. 2016. 
4. Perelini F, Blair N, Wilson N, et al. Family acceptability of school-based echocardiographic screening for rheumatic heart disease in a highrisk population in new zealand: Rheumatic heart disease screening. $J$ Paediatr Child Health. 2015;51(7):682-688.

5. Nulu S, Bukhman G, Kwan GF. Rheumatic Heart Disease: The Unfinished Global Agenda. Cardiol Clin. 2017;35(1):165-180.

6. Hunter LD, Monaghan M, Lloyd G, et al. Screening for rheumatic heart disease: Is a paradigm shift required? Echo Res Pract. 2017;4(4):R43R52.

7. Pan American Health Organization. Health in the Americas. 2012.

8. Millard-Bullock. The rheumatic fever and rheumatic heart disease control programme: Jamaica. West Indian med j. 2012;61(4).

9. Dale JB, Batzloff MR, Cleary PP, et al. Current Approaches to Group A Streptococcal Vaccine Development. In: Ferretti JJ, editors. Streptococcus pyogenes : Basic Biology to Clinical Manifestations. Oklahoma City (OK): University of Oklahoma Health Sciences Center; 2016.

10. Manji RA, Witt J, Tappia PS, et al. Cost- effectiveness analysis of rheumatic heart disease prevention strategies. Expert Rev Pharmacoecon Outcomes Res. 2013;13(6):715-24.

11. Marijon E, Mirabel M, Celermajer DS, et al. Rheumatic heart disease. Lancet. 2012;379(9819):953-964.

12. Chang C. Cutting edge issues in rheumatic fever. Clin Rev Allergy Immunol. 2012;42(2):213-237.

13. World Pediatric Project. 2017.

14. Reményi B, Wilson N, Steer A, et al. World Heart Federation criteria for echocardiographic diagnosis of rheumatic heart disease-an evidencebased guideline. Nat Rev Cardiol. 2012;9(5):297-309.

15. Irlam J, Mayosi BM, Engel M, et al. Primary prevention of acute rheumatic fever and rheumatic heart disease with penicillin in south african children with pharyngitis: A cost-effectiveness analysis Circulation Cardiovascular Quality and Outcomes. 2013;6(3):343.

16. Watkins DA, Mvundura M, Nordet $\mathrm{P}$, et al. A cost-effectiveness analysis of a program to control rheumatic fever and rheumatic heart disease in pinar del rio, cuba. PLoS One. 2015;10(3):e0121363.

17. Nitsche-Schmitz D, Sharma A. Challenges to developing effective streptococcal vaccines to prevent rheumatic fever and rheumatic heart disease. Vaccine: Development and Therapy. 2014;4:39-54.
18. Strep throat. 2018

19. Secondary prevention of acute rheumatic fever. 2nd ed. Casuarina: RHD Australia; 2012.

20. Dhanda V, Chaudhary P, Toor D, et al. Antimicrobial susceptibility pattern of $\beta$-haemolytic group A, C and G streptococci isolated from North India. J Med Microbiol. 2013;62(Pt 3):386-393.

21. Joseph N, Madi D, Kumar GS, et al. Clinical spectrum of rheumatic Fever and rheumatic heart disease: A 10 year experience in an urban area of South India. N Am J Med Sci. 2013;5:647-652.

22. Saxena A, Mehta A, Ramakrishnan S. Adherence to benzathine penicillin in children with rheumatic fever/rheumatic heart disease: Results from an Indian pediatric RHD registry. JACC. 2015;65(10).

23. Engelman D, Kado JH, Reményi B, et al. Focused cardiac ultrasound screening for rheumatic heart disease bybriefly trained health workers: A study of diagnostic accuracy. The Lancet Global Health. 2016;4(6).

24. Beaton A, Nascimento BR, Diamantino AC, et al. Efficacy of a Standardized Computer-Based Training Curriculum to Teach Echocardiographic Identification of Rheumatic Heart Disease to Nonexpert Users. Am J Cardiol. 2016;117(11):1783-1789.

25. Gasse B, Baroux N, Rouchon B, et al. Determinants of poor adherence to secondary antibiotic prophylaxis for rheumatic fever recurrence on Lifou, New Caledonia: A retrospective cohort study. BMC Public Health. 2013;13:131.

26. James C, Boardman C. What is acute rheumatic fever (ARF) and rheumatic heart disease (Rheumatic heart disease)? Australian Nursing and Midwifery Journal. 2016; 23(8):41

27. https://www.worldpediatricproject.org/

28. NATIONAL REPORT ST. VINCENT AND THE GRENADINES [PDF] (2013). Kingstown: Ministry of Health Wellness and the Environment .

29. Robinson L. Medical \& Health Care. 2018

30. Saint Vincent and the Grenadines Travel Information. 2018

31. Sriha Belguith A, Koubaa Abdelkafi A, El Mhamdi S, et al. Rheumatic heart disease in a developing country: Incidence and trend (monastir; tunisia: 2000-2013). Int J Cardiol. 2017;228:628-632.

32. St Vincent and the Grenadines, Population and Housing Census Preliminary Report.

33. SVG Essentials. 2018. 